\title{
Promoting Word Consciousness to Close the Vocabulary Gap in Young Word Learners
}

\author{
Perla B. Gámez \\ Loyola University Chicago, pgamez@luc.edu \\ Sabina Rak Neugebauer \\ Temple University \\ Michael D. Coyne \\ University of Connecticut \\ D. Betsy McCoach \\ University of Connecticut \\ Ingrid T. Cólon \\ University of the District of Columbia
}

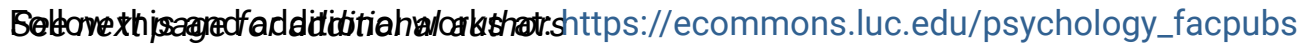

Part of the Psychology Commons

\section{Recommended Citation}

Gámez, Perla B.; Neugebauer, Sabina Rak; Coyne, Michael D.; McCoach, D. Betsy; Cólon, Ingrid T.; and Ware, Sharon. Promoting Word Consciousness to Close the Vocabulary Gap in Young Word Learners. The Elementary School Journal, 118, 1: 28-54, 2017. Retrieved from Loyola eCommons, Psychology: Faculty Publications and Other Works, http://dx.doi.org/10.1086/692986

This Article is brought to you for free and open access by the Faculty Publications and Other Works by Department at Loyola eCommons. It has been accepted for inclusion in Psychology: Faculty Publications and Other Works by an authorized administrator of Loyola eCommons. For more information, please contact ecommons@luc.edu. cc) (i) $९$

This work is licensed under a Creative Commons Attribution-Noncommercial-No Derivative Works 3.0 License. (C) The University of Chicago 2017 


\section{Authors}

Perla B. Gámez, Sabina Rak Neugebauer, Michael D. Coyne, D. Betsy McCoach, Ingrid T. Cólon, and Sharon Ware 


\section{PROMOTING WORD CONSCIOUSNESS TO CLOSE THE VOCABULARY GAP IN YOUNG WORD LEARNERS}

\begin{abstract}
A B S T RACT
A proposed avenue for increasing students' vocabulary knowledge and reading comprehension is instruction that promotes students' enthusiasm and attention to words, referred to as word consciousness. This study seeks to investigate, at the utterance level, whether and how word consciousness talk is used in classrooms with young word learners and whether this type of talk is associated with student gains in general vocabulary knowledge. Using videotaped classroom $(N=27)$ observations, this study found evidence of word consciousness talk, with variability of use across classrooms. Multilevel modeling revealed that this kind of teacher talk - operationalized as reinforcing students' use of words, affirming students' recognition of word meanings, and helping students make personal connections to words - was positively associated with student gains in general vocabulary knowledge at the end of kindergarten. Findings from this study can provide guidance for teachers seeking strategies to increase students' general vocabulary knowledge, beyond words taught.
\end{abstract}

Sabina Rak Neugebauer

TEMPLE UNIVERSITY

Perla B. Gámez

LOYOLA UNIVERSITY CHICAGO

Michael D. Coyne

UNIVERSITY OF

CONNECTICUT

Ingrid T. Cólon

UNIVERSITY OF THE

DISTRICT OF COLUMBIA

D. Betsy McCoach

UNIVERSITY OF

CONNECTICUT

Sharon Ware

UNIVERSITY OF

SAINT JOSEPH

THE ELEMENTARY SCHOOL JOURNAL

Volume 118, Number 1. Published online August 14, 2017

(C) 2017 by The University of Chicago. All rights reserved. 0013-5984/2017/11801-0002 $\$ 10.00$ 
$\mathrm{T}$

H E positive association between vocabulary knowledge and literacy-related outcomes is well documented (Johnston \& Kirby, 2006; Ouellette \& Beers, 2010). Students who enter school with smaller vocabularies tend to be at higher risk for school failure, with the discrepancy between these students and their peers with greater vocabularies growing larger over time (Hart \& Risley, 1995). Notably, these differences between children with relatively low vocabularies and their peers with high vocabularies have already occurred by age 3 (Fernald, Marchman, \& Weisleder, 2013; Hart \& Risley, 1995). Thus, to close the discrepancy between learners, it is important to determine best practices for increasing students' vocabulary in early education settings.

Research and practice focused on improving students' vocabulary knowledge indicates that to sufficiently boost students' word knowledge, instruction must not only improve students' knowledge of words taught in the curriculum but also increase students' strategies and enthusiasm for learning new words in naturally occurring contexts (Coyne, McCoach, Loftus, Zipoli, \& Kapp, 2009). Thus, a proposed avenue for increasing students' general vocabulary knowledge is through classroom instruction that promotes students' interest in and attention to words, referred to as word consciousness (Scott \& Nagy, 2004). More specifically, "word consciousness integrates metacognition about words, motivation to learn words, and deep and lasting interest in words" (Graves \& Watts-Taffe, 2008, p. 186). The theorized benefits of promoting word consciousness include heightened student excitement about words that can lead to students' absorbing and retaining words taught and those they are exposed to incidentally (Graves, 2006).

Existing studies have demonstrated the success of instruction that enhances students' word consciousness on improving vocabulary knowledge and reading comprehension (Scott \& Nagy, 2004; Scott, Miller, \& Flinspach, 2012; Zipke, 2008). Yet these studies have largely focused on older word learners (i.e., in late elementary, middle, and high school), a population for whom these strategies may be remedial as opposed to preventive. These existing studies have also required substantial teacher expertise or training and curriculum development and may not reflect common teacher language use in early elementary settings (Dickinson \& Porche, 2011). Thus, little is known about the types of teacher talk that might promote word consciousness for young word learners (students beginning their formal schooling) and the potential contribution of this kind of teacher talk for promoting students' general vocabulary knowledge, possibly preventing reading difficulties at later stages of development.

This study seeks to investigate whether and how teachers' language in kindergarten classrooms includes a focus on word consciousness and whether teacher talk that promotes word consciousness is associated with gains in students' general vocabulary knowledge in kindergarten. In what follows, we review the literature on how word consciousness has been defined in the field, in particular, how it differs from other word-learning strategies and, relatedly, how this construct has been operationalized across studies (i.e., through teacher activities). We will then address why this study takes a unique approach to exploring this construct by examining word consciousness at the utterance level in everyday teacher-student interactions and describe how word consciousness teacher talk is likely related to but distinct from other high-quality teacher characteristics. We review these bod- 
ies of work together to elaborate on how this construct has been explored in the past and the potential of alternative ways of operationalizing this concept for future work.

Limited empirical attention has focused on this area of research, with only a handful of studies explicitly testing the unique contribution of word consciousness to student vocabulary knowledge, and all with older word learners (Baumann, Ware, \& Edwards, 2009; Scott et al., 2012; Walsh, 2014). This synthesis of the literature lays the groundwork for exploring word consciousness in everyday interchanges with students and thereby furthers work to directly test the potential of word consciousness teacher talk to contribute to generative word learning.

\section{Defining Talk to Promote Word Consciousness}

According to Scott and Nagy (2004, p. 201), at the core of word consciousness are "dispositions necessary for students to learn, appreciate, and effectively use words." However, instruction focused explicitly on increasing students' dispositions to learn vocabulary is often overlooked and infrequently clearly defined or measured in instructional programs. In a rare example of a vocabulary intervention that explicitly identifies word consciousness as a central component, Graves (2006) distinguishes between word consciousness and commonly implemented research-based vocabulary practices in which teachers might say and discuss the definition of a word, show pictures of that word, contrast the word with other words, teach context clues to figure out the word's meaning, and read more about the word in a thematically related text (i.e., explicit definitions, wide reading of target words, and wordlearning strategies). Word consciousness most markedly distinguishes itself from these other features of an instructional program in that it focuses on instruction to support dispositions or affective aspects of word learning.

A few studies of vocabulary programs have addressed students' word consciousness through various word-based activities (Baumann et al., 2009; Graves \& WattsTaffe, 2008). Instructional activities that have been hailed as contributing to students' enthusiasm about words include use of riddles or puns to make word learning engaging (Blachowicz \& Fisher, 2004; Scott \& Nagy, 2004; Zipke, 2008) and encouraging students to collect and track sophisticated vocabulary words outside of school as a way to make word learning more relevant to their lives (Graves, 2006; McKeown, Crosson, Artz, Sandora, \& Beck, 2013). These activities are thought to increase students' interest and curiosity about words, which makes them more likely to attend to words in their environment, as well as in their speech, writing, and reading. Such dispositions toward words, thus, may be seen as both affective and cognitive in nature.

Activities that increase only students' metacognition about words, a cognitive component of word consciousness, are less agreed upon by scholars, with the exact definition of this construct contributing to these debates. To elaborate, some scholars view activities to support morphological awareness (prefixes, suffixation, and root words), to improve students' syntactic awareness using word definitions (Scott \& Nagy, 1997), and to understand the words synonym and antonym or metaphor through semantic mapping (Nagy \& Scott, 2000; Zipoli, Coyne, \& McCoach, 2011) 
as activities that promote students' word consciousness. However, other scholars see these as word-learning strategies, that is, active ingredients in research-based vocabulary interventions to support curriculum-specific word learning and do not characterize these parts of the curriculum as word consciousness activities per se (Graves \& Watts-Taffe, 2002; Kieffer \& Lesaux, 2010; Silverman, 2007). Of note for the present investigation is that many existing evidence-based vocabulary programs include some or all of these word-learning strategies (Beck \& McKeown, 2004; Silverman, 2007; Zipoli et al., 2011). Yet, unexplored in the majority of these programs is instruction to support the dispositional component of word consciousness - either in the program design or in components that are measured and observed. As such, the present study was specifically focused on the ways in which teachers explicitly promote students' interest and motivation to engage with words and the contribution of these teacher practices for word learning beyond curriculumspecific words.

\section{Teacher Talk to Foster Word Consciousness}

The existing literature on supporting students' developing word consciousness provides examples of specific activities that are theorized to improve word consciousness. However, less is known about how teachers' everyday language use can promote this disposition toward words. To date, no studies have explored the concept of word consciousness as it relates to teacher talk, that is, a more fine-grained analysis of student-teacher exchanges. This approach to word consciousness is consistent with the work of scholars who argue that word consciousness should not be framed solely as a specific activity or an additional component of the literacy routine or program (as it is in the studies just mentioned and in the broader literature) but also as discussions about words that are occurring all day (Scott \& Nagy, 2004).

Research on teacher discourse and teacher-student interactions in the classroom provide compelling evidence for the potential of exploring word consciousness talk for understanding student learning. For example, in a canonical study with fifthgrade teachers providing instruction on the same language and literacy skills, Duffy, Roehler, and Rackliffe (1986) found that even when teachers used comparable overt behaviors (activities, time allocation, and routines), the differences in the ways they talked about content were what affected students' developing knowledge. Specifically, teacher talk that included real-world applications and verbal elaborations of reasoning processes resulted in stronger student understanding of literacy skills. A more recent study by Wasik and Hindman (2014) found similar results for the importance and impact of certain kinds of teacher talk on learning. These authors found that preschool teachers' repetitions of children's remarks were associated with higher student standardized vocabulary scores above and beyond decontextualized and contextualized teacher statements (Wasik \& Hindman, 2014). The findings from both of these studies support the importance of teacher talk for students' learning and more specifically talk that may be seen as increasing motivational components of learning. In the case of the former, students were more likely to retain information when they saw it as relevant to themselves, and in the case of the latter, teachers' verbal validations - through repetition and elaboration- 
of students' knowledge, the authors argue, may have reinforced the importance of words by endorsing student contributions (Wasik \& Hindman, 2014). Relatedly, in a study by Silverman (2007) to explore three different approaches to vocabulary instruction, teacher questioning that prompted students to connect words from texts to their own background knowledge was taught across all three conditions and, when taught in conjunction with other research-based vocabulary practices, demonstrated a significant association with curriculum-specific vocabulary. The positive findings from this study bolster arguments for the potential of this combined approach for increasing young students' interest in words by enhancing their sense of a word's meaningfulness and potential application to their lives (Guthrie et al., 2007).

Despite this compelling existing evidence of the potential of teacher talk to support motivational components of word learning and calls in the literature for teacher language that promotes word consciousness to be more pervasive in teacherstudent interactions, few studies use teacher utterances as the unit of analysis for exploring the content of teachers' talk (Gámez \& Lesaux, 2015; Snow \& Dickinson, 1991) and none to investigate word consciousness. Critical for developing this field, and ultimately increasing students' dispositions toward learning new words, is an understanding of teachers' everyday language use that can promote students' word consciousness.

To support teachers in integrating talk that promotes word consciousness throughout daily school-based interactions, research must identify and characterize this kind of talk, beyond scripted curriculum-specific activities, by examining whether teacher language to support word consciousness occurs in classroom discussions about words. An exploration of teachers' language to promote word consciousness provides an opportunity for a more fine-grained analysis of the multifaceted nature of teacher discourse that supports interest in words and, by extension, attention to words, as vocabulary interventions have not separately explored the association between these components of teachers' word consciousness talk and student learning.

\section{Teacher Word Consciousness Talk as Separable from Other Teacher Talk}

Essential to defining and understanding the potential impact of teacher talk to promote word consciousness on vocabulary outcomes is distinguishing it from other related aspects of teacher talk. For instance, it is reasonable to expect that a teacher who emphasizes word consciousness and cultivates enthusiasm about words might respond to a student's "Good morning" with "Salutations, and greetings!" Such a teacher not only promotes word consciousness but also probably uses many words. There is likely considerable overlap between teachers who use many words in their teaching and teachers who intentionally try to stimulate students' interest in words. As such, these two aspects of teacher talk are likely related. However, it is also possible that there are certain teachers who may use a lot of words in the classroom but may not necessarily draw students' attention to the importance or power of words to express ideas. 
In addition, a teacher who commonly encourages students' interest in words might respond to a student showing off her new birthday present and describing how enormous it is with, "Enormous is the perfect word to describe your huge new blocks!" This same teacher may also be more sensitive to and aware of students' emotional needs more broadly. A sensitive teacher is more likely to acknowledge students' contributions, verbal and behavioral, and respond in a soothing manner regardless of the content being discussed (Bryant, Clifford, Early, Howes, \& Pianta, 2002). Thus, it is likely that there is some overlap between teachers who are affectively attuned to students in general and those who are specifically validating or motivating in their talk about words. Yet it is also possible that teachers who are generally responsive and sensitive to students' emotional needs may validate students' contributions with "Great job!" but without a focus on or enthusiasm for words in particular, and as such, these teachers may not explicitly reinforce word use specifically and in ways that are direct enough for students to perceive.

These teacher characteristics, particularly responsiveness to students' needs, have been repeatedly found to influence students' academic development (Pianta, 2003). A central question for understanding talk to promote word consciousness is whether such talk may uniquely be associated with students' vocabulary growth. Thus, this study seeks to investigate whether teachers' language in classrooms with young word learners includes a focus on affective aspects of word consciousness and whether instruction to enhance students' interest in words is a source of variation in students' general vocabulary knowledge when accounting for these other teacher characteristics, for example, responsivity.

\section{Theoretical Framework for Teacher Talk and Word Consciousness Constructs}

This study draws from the work of Vygotsky (1986) to support the idea that word learning occurs as a function of social interactions with others. Empirical and theoretical research substantiates this strong association between quality of classroom talk and student understanding and learning (e.g., Mercer, 2002). Particularly relevant for the framing of the present study is that teachers produce the majority of language in classrooms (Silverman et al., 2014), making an exploration of the ways teachers are talking particularly relevant for understanding students' developing word consciousness.

\section{Word Consciousness and Engagement Theory}

The theoretical framework that guides this study of word consciousness is literacy engagement theory. Views of engagement theory include multiple perspectives on literacy, with two common ingredients for engagement that cut across these diverse lenses being that engaged students are active and energized to immerse themselves in the focal literacy task and that they use their minds (Guthrie, 2004). Particularly relevant for this investigation and synergistic with the work of Vygotsky (1986), theories of literacy engagement support social interactions between student and 
teacher as essential for energizing students to improve their performance (Guthrie \& Humenick, 2004; Guthrie \& Wigfield, 2000). Teachers' appreciation and recognition of student behaviors - in this case, student word use, knowledge, or attention to words - is posited to increase students' sense of competence (Tracey \& Morrow, 2006), with perceived competence being highly correlated with student performance (Bandura, 1997). For instance, in an observational study with second- and fourth-grade students, teacher talk was coded for positive praise, among other forms of feedback, and the relation between praise and students' self-reported perceptions of reading and math ability (Pintrich \& Blumenfeld, 1985). Findings indicated that teachers' praise of student behavior resulted in higher self-perceptions of ability. Specifically as it relates to word use, an intervention study with fourth-grade students found that when receiving verbal praise for a game focused on increasing interest in wordplay (creating funny endings to riddles), students chose to complete more riddles compared with a baseline period when they did not receive such praise (Sarafino, Russo, Barker, Consentino, \& Titus, 1982). These studies together demonstrate that teachers' feedback has an impact on students' interest in the task.

Engagement theory also highlights the central role of building on students' personal experiences and interests to increase learning: "When students make connections between the material they are reading and their lives, they become more involved and engaged in comprehending text" (Gambrell, 2011, p. 66). Applied to vocabulary learning for early and prereaders, connections between students' personal experiences and words that speak to these experiences or can be used to talk and think about these experiences have been incorporated in previous efficacious vocabulary programs (Beck, McKeown, \& Kucan, 2002; McKeown \& Beck, 2014). Literacy engagement theorists hail positive feedback and making personal connections as useful practices for increasing student learning (Gambrell, 2011), and vocabulary researchers espouse personal connections as an essential practice (Beck et al., 2002; Nagy \& Scott, 2000). Yet less is known about the contribution of these types of utterances (i.e., recognizing and affirming student word contributions as well as providing students with opportunities to personally connect with words) to the vocabulary learning of young learners, in naturally occurring contexts, than is known about their collective benefit with other successful components of a comprehensive vocabulary program.

\section{This Study}

This study aimed to identify everyday teacher talk that promotes word consciousness and to investigate whether teacher talk to promote word consciousness is positively associated with gains in students' general vocabulary knowledge in kindergarten. Research indicates that very little instructional time is devoted to vocabulary instruction, and the vast majority of such instruction is brief and superficial (Feldman \& Kinsella, 2005; Kucan, 2012). Therefore, this study required a purposeful context for capturing teacher vocabulary talk, with time specifically allotted to vocabulary instruction in the curriculum. This investigation sought to capture individual differences in teachers' language use that might promote word consciousness, within an instructional context with allocated vocabulary time that provided a 
rich opportunity to observe potential variability in teacher language (McKeown, Beck, \& Apthorp, 2011). Thus, this study is situated in the context of a vocabulary program, which provided more occasions of extended talk about words and, equally important, permitted an explicit look at the contribution of word consciousness above and beyond common research-based activities included in vocabulary programs. Specifically, this study examined what teacher utterances to support word consciousness might look like for teachers of younger learners and whether such talk to promote word consciousness is associated with differences in students' general vocabulary knowledge. To do so, this study explores the following research questions: (1) How do kindergarten teachers use language to promote word consciousness? (2) In what ways does teacher talk to promote word consciousness vary across classrooms as a function of the type of word-conscious talk? (3) Is teacher word consciousness talk uniquely associated with students' general vocabulary knowledge at the end of kindergarten?

\section{Method}

This study explored the potential benefits of teacher talk to promote word consciousness during designated vocabulary time. Participating teachers used the same schoolwide vocabulary program: the Elements of Reading Vocabulary (EORV) program (Beck \& McKeown, 2004). This program teaches students five vocabulary words per week during 5-day lessons for a total of 24 weeks and a new set of five words each week. Words are introduced during a read-aloud activity and reviewed throughout the week with activities using picture cards, graphic organizers, and semantic maps. Noteworthy for the aims of our study is that the EORV program is not an explicitly scripted program. In the absence of a daily script, our aim was to capture teacher talk that might promote word consciousness - generative vocabulary talk intended to support word learning broadly - in the context of instructional time specifically allotted to vocabulary development (McKeown et al., 2011).

\section{Classroom Context and Sample}

This study draws from data collected as part of two larger studies. Studies 1 and 2 investigated a multitier system-of-supports framework for vocabulary instruction. In these studies, teachers delivered vocabulary instruction to all students in the core classroom (Tier 1) using the EORV program, and a selected group of children who scored below the thirtieth percentile on the Peabody Picture Vocabulary Test, fourth edition (PPVT-4; Dunn \& Dunn, 2007) at the beginning of kindergarten received a supplemental researcher-developed small-group intervention (Tier 2) delivered by interventionists. More specifically, Study 1 was composed of a stratified sample of students that included a subsample of students $(n=15)$ who fell below the thirtieth percentile on the PPVT-4 (i.e., students at risk for vocabulary difficulties) and a subsample of typically developing students $(n=162)$ who scored above the thirtieth percentile on the PPVT-4, for a total of 177 students in Study 1 . Study 2 included a randomly assigned group of students $(n=91)$ who scored above the 
thirtieth percentile and a randomly assigned group of students $(n=99)$ who fell below the thirtieth percentile.

The present investigation focuses on students in Studies 1 and 2 who were at risk for vocabulary difficulties and who were typically developing that only received Tier 1 instruction $(n=244)$. The larger studies included at-risk students $(n=$ 116) who received Tier 2 instruction in addition to Tier 1 instruction. Our sample for investigation included students with a range of vocabulary scores, with $28 \%$ of the current sample considered at risk for vocabulary difficulties based on their performance on the PPVT-4. Teachers across studies implemented the EORV vocabulary lessons in their classrooms.

This study examines the videotaped lessons of 27 of the 48 teachers in the two larger studies, teachers who taught in urban schools. We were particularly interested in examples of teacher talk that promotes word consciousness in urban classrooms. We chose to focus specifically on urban classrooms with high numbers of historically underserved students because less is known about the language supports provided by teachers in these environments and because this population of students, on average, is at elevated risk for language and literacy difficulties (Snow, Burns, \& Griffin, 1998). Two teachers were excluded from an original sample of 29 because their taped observations occurred on days when they conducted an assessment and word study review session. Of the final 27 participating teachers, 23 identified as White and 4 identified as African American; 26 identified as female and 1 identified as male. Participating teachers had an average of 13.82 years of teaching experience, with 1 teacher not reporting her years of experience; 26 had a master's degree, and 1 had only a bachelor's degree. All teachers who reported their years of experience, with the exception of one teacher, had 5 years or more experience teaching.

Across the 12 schools that participated in the study, the numbers of teachers ranged from one to three at each school, and included a total of 215 kindergarten students (fall mean age $=5$ years, 5 months), with the average class size ranging from 17 to 22 students ( $M=20$ students). The final student population $(N=215)$ was $29 \%$ White, $27 \%$ African American, 36\% Latino, and $7 \%$ other, with $49 \%$ female and 51\% male (see Table 1).

\section{Data Collection and Procedures}

To capture teachers' word consciousness talk, 20-minute videotaped classroom observations $(M=22.38, S D=9.56)$ of the daily vocabulary time were collected approximately midway through the kindergarten year. Classroom studies support the use of one observation in the context of generative language practices (Bowers \& Vasilyeva, 2011; Dickinson \& Smith, 1994). Research bolstering the use of one observation point to capture language characteristics indicates that adult language with young children appears to be relatively stable over time, with greater variability occurring between individuals (Huttenlocher, Vasilyeva, Waterfall, Vevea, \& Hedges, 2007). Further, this study explored in detail 20 minutes of talk; in studies of classroom discourse, excerpts of 20 minutes of talk are often considered substantive, given the fine-grained nature of discourse analysis (Walsh, 2014). 
Table 1. Demographic Characteristics of Teacher and Student Samples

\begin{tabular}{lc}
\hline Demographic & Result \\
\hline Teachers $(N=27)$ : & \\
Race/ethnicity (\%): & 85 \\
White & 15 \\
$\quad$ African American & 96 \\
Female gender (\%) & \\
Education (\%): & 4 \\
$\quad$ Bachelor's & 96 \\
$\quad$ Master's & 13.82 \\
Average teaching experience, years & \\
Students $(N=215):$ & \\
Race/ethnicity (\%): & 29 \\
$\quad$ White & 27 \\
$\quad$ African American & 36 \\
$\quad$ Latino & 7 \\
Other & 49 \\
Female gender (\%) & 28 \\
Vocabulary, at risk (\%) & \\
\hline
\end{tabular}

Videotaped classroom observations were coded for multiple features of teacher talk. The Classroom Assessment Scoring System (CLASS) was used to code teacher videos for teacher sensitivity, and videos were transcribed and coded for incidences of teachers promoting word consciousness (coding scheme described in Measures) as well as teachers' word use. Students were administered a standardized vocabulary assessment at kindergarten entry and again in the spring. Student demographic information was also collected from teachers at the start of the kindergarten year.

\section{Measures}

Peabody Picture Vocabulary Test, fourth edition. The PPVT-4 (Dunn \& Dunn, 2007) is a commonly used standardized norm-referenced, individually administered test of receptive language and vocabulary. Each test item contains four illustrations. The student is asked to point to the picture that best represents the meaning of the word presented by the examiner. Test-retest reliability for the PPVT- 4 is .77 , and alternate form reliability is .82 . Overall, research suggests adequate evidence of reliability and validity for the PPVT-4 (Salvia \& Ysseldyke, 1998). The PPVT-4 was used to determine students' vocabulary ability upon entering kindergarten as well as their scores at the end of kindergarten.

Videos and transcripts of teacher observations. Teachers' language use was transcribed from 20-minute videotaped observations of the 20-minute daily kindergarten literacy period. These videotaped teacher-child interactions were transcribed by two research assistants. They worked with an experienced transcriber for approximately 10 hours to complete practice transcripts before coding the data. Each transcript was carefully reviewed for accuracy by an independent and reliable transcriber who received extensive training — 30 to 40 hours (see Rowe, 2012) — with reliability testing including $90 \%$ agreement on independently transcribed files. 
The transcripts were formatted to adhere to a modified version of the Codes for the Human Analysis of Transcripts (CHAT) conventions of Child Language Data Exchange System (CHILDES; MacWhinney, 2010), including breaking speech into utterances (i.e., units of speech bounded by breaths/pauses, intonation, and conversational turns) that indicate a break in the flow of speech. Teachers' language included the use of read-aloud activities and spontaneous talk as well as the use of daily vocabulary words.

Teacher word consciousness codes. To code for word consciousness, we used an iterative process of content analysis (Krippendorff, 2012; Neuendorf, 2002; Schreier, 2012). Content analysis requires that data must be "chunked" or broken into units that allow for the coding and analyzing of data. Our central focus in this study was teacher talk, and thus we selected the utterance as the unit of analysis, a unit that has been found in other studies on teacher talk to provide insight into teachers' instructional focus via student-teacher interchanges (Silverman et al., 2014). Notably, previous studies that have explored word consciousness, including the extant work by Graves and Watts-Taffe (2002) as well as by Scott and Nagy (2004), have explored this construct as it relates to teacher activities but have not applied this analytic construct to an exploration of teacher utterances. Of interest for the present investigation was teacher language that explicitly fosters word consciousness. As such, we did not code teacher intentions or actions but teachers' explicit verbal messages to students that fostered word consciousness. To elaborate, we did not focus on how they interacted with materials or their presumed pedagogical purposes (e.g., having students look for the magic words around the classroom or using picture cards of fast, fun cars to connect the word to an engaging image) but how they talked about language (e.g., "Kiss your brain, that was a wonderful example of glimmer," or "Can you tell me more about how you might be active when you are spending time with your little brother?").

We used Graves and Watts-Taffe's (2002, p. 145) work that suggests teacher instruction to support word consciousness should focus on "modeling, recognizing, and encouraging adept diction" as an initial construct for identifying codable utterances. We explored a randomly selected subsample of transcripts, identifying word consciousness teacher utterances and coding them by types of teacher talk that emerged (i.e., affectively explicit talk to encourage adept diction, and explicit metacognitive talk that models and recognizes adept diction). Through an exploration of the transcripts, the research team iteratively developed substantive and theoretical categories (Maxwell, 2005), expanding and refining the affectively explicit codes (i.e., affirming word recognition, reinforcing word use, and making personal connections), drawing support from engagement theory, which emphasizes the use of verbal praise and making content relevant to students. The metacognitive codes were also refined (i.e., use of multiple synonyms, sentence with a definition, juxtaposing two words, idea of a word, evoking idea of a synonym); however, these codes, consistent with critiques in the literature, seemed to overlap considerably with common vocabulary program features (e.g., providing a definitional sentence for a new word is standard practice for any vocabulary program), and thus we focused our investigation on the affective codes that emerged. We used codes grounded in the engagement literature to classify different types of teacher talk that might operationalize talk to promote word consciousness at the utterance level, allowing 
for a more fine-grained understanding of the kinds of messages expressed by teachers about words.

Based on this process, word consciousness teacher talk was coded as talk that explicitly $(a)$ positively reinforced word use, $(b)$ affirmed students' word recognition, and $(c)$ made connections between words and students' personal experiences. Once these substantive and theoretical categories were defined, exemplars of each category from the data were compiled to anchor these codes. The coding team met to revise and amend codes collectively. Once a final codebook had been created, each transcript was coded twice by two separate coders. All discrepancies were discussed, and disagreements in coding were resolved by group consensus. Interrater reliability based on $20 \%$ of the total cases was $91 \%$.

Word consciousness scoring. In analyzing the mean frequencies of the three codes to promote word consciousness across classrooms, we created a relative frequency for the 20-minute observations. That is, we calculated the total frequency count of a type of word consciousness teacher talk per classroom, multiplied that number by the average number of minutes of a lesson (i.e., 20), and divided by the number of minutes in the actual observation. This calculation facilitates the interpretability of the mean score per code across classrooms by permitting equivalent comparisons across classrooms. However, for our third research question regarding the association of word consciousness talk with student vocabulary performance, the three word consciousness codes were calculated as the total frequency count in an observation and were included as a composite score to address the low base rate scores on two of the indicators.

Teacher sensitivity. Videos of the teacher observations were coded using the CLASS (Pianta, LaParo, \& Hamre, 2008b). This measure and its corresponding subscales have been found to demonstrate construct validity, are reliable across age groups, and are associated with academic and social performance measures (Burchinal et al., 2008; Mashburn et al., 2008; Pianta et al., 2005). This measure is composed of 10 dimensions (i.e., positive climate, negative climate, teacher sensitivity, regard for student perspectives, behavior management, instructional learning formats, productivity, concept development, quality of feedback, and language modeling) that are rated on a 7-point scale from low to high. For the purpose of our examination, we were particularly interested in the teacher sensitivity scale, as this subscale captures "teachers' awareness of and responsivity to students' academic and emotional concerns" (Pianta, La Paro, \& Hamre, 2008a, p. 3). This dimension has been correlated with literacy skills (Pianta, 2003) and captures emotionrelated aspects of the classroom. By including this indicator of teaching quality that captures emotive components of the classroom, we were interested in teasing out the potentially unique contribution of talk focused exclusively on increasing students' motivation to engage with words on vocabulary performance, beyond just supportive teacher commentary. Videos were coded by a CLASS trainer, certified by the developer, with more than 5 years' experience using the CLASS. According to the CLASS manual, trained coder interrater reliability for teacher sensitivity, for ratings within 1 point of each other, was $\alpha=.818$, with subsequent studies replicating an almost identical estimate (Pianta et al., 2008b).

Word use (types). To capture the diversity of teachers' use of words, the Computerized Language Analysis (CLAN) software program (MacWhinney, 2010) was 
used to derive the number of different word types used by each teacher (names and letters/letter sounds were excluded from this count).

EORV instruction fidelity. To account for other instructional indicators of classroom quality, we also captured teachers' fidelity to the vocabulary program with a surface fidelity measure (Gersten et al., 2009). Specifically, an observation checklist was developed that included four salient dimensions of the vocabulary program. In particular, teachers were assessed on whether or not they $(a)$ used appropriate materials, $(b)$ explained or modeled activities, $(c)$ provided students with opportunities to practice words, and $(d)$ completed all procedural components of the activity. For any given day, the activity list included three to four activities (e.g., reading stories, reviewing target words, writing about target words). Each activity was scored for the presence or absence of the four dimensions listed, with a possible score of either 12 (three activities) or 16 (four activities). Given the difference in possible scores by day, instruction fidelity was calculated as the total actual score divided by the total possible score and explored as a control in our model as the percentage implemented. This measure captures aspects of instruction hypothesized to be distinct from talk that promotes word consciousness, as it records activity-related features (materials and routines) of the classroom. Interrater reliability for EORV instruction fidelity demonstrated acceptable reliability $(\alpha=.87)$ and has been found to be reliable in previous studies (i.e., coefficient $\kappa=.93$; Coyne et al., 2010).

\section{Data Analysis Plan}

To answer our first question, regarding whether and how kindergarten teachers use talk to promote word consciousness, we descriptively capture the different types of word consciousness talk that emerged from the transcripts. For our second research question, related to the variability across classrooms, we analyzed the frequency of use of these kinds of talk across classrooms. For our third research question, regarding the association between word consciousness teacher talk and students' general vocabulary knowledge at the end of kindergarten, we estimated multilevel models (Singer \& Willett, 2003). Specifically, we used the PROC MIXED statement in SAS 9.3, nesting students within classrooms to explore student performance outcomes (Level 1) as a function of both Level 1 predictors (student previous performance and demographic variables) and Level 2 predictors (word consciousness talk codes, teacher sensitivity, surface fidelity of classroom program activities, and teachers' word types). We present our findings, including descriptive statistics for these instructional codes and frequency and prevalence of these codes across classrooms, and our taxonomy of models exploring the association between word consciousness talk and general vocabulary knowledge at the end of kindergarten.

\section{Results}

\section{Descriptive Statistics}

Classroom vocabulary scores. Table 2 shows that the receptive vocabulary (PPVT-4) raw scores from the fall $(M=86.51, S D=19.69)$ were statistically significantly different from the spring raw PPVT scores $(M=99.05, S D=19.40)$, 
Table 2. Means for Teacher Talk Codes and Student Performance

\begin{tabular}{lcccr}
\hline & Mean & $S D$ & Min & Max \\
\hline Teacher variables: & & & & \\
$\quad$ Reinforcing use & 1.00 & 1.13 & 0 & 4 \\
Personal connections & 4.18 & 9.19 & 0 & 30 \\
Affirming word recognition & 1.66 & 2.14 & 0 & 12 \\
Teacher sensitivity & 4.95 & 1.13 & 2 & 6 \\
$\quad$ Word types & 453.17 & 108.05 & 190 & 684 \\
Instruction fidelity & .83 & .18 & .30 & 1.0 \\
Student variables: & & & & \\
Fall: & & & & \\
$\quad$ PPVT-4 raw score & 86.51 & 19.69 & & \\
$\quad$ PPVT-4 standardized score & 100.19 & 14.19 & & \\
Spring: & & & & \\
$\quad$ PPVT-4 raw score & 99.05 & 19.40 & & \\
PPVT-4 standardized score & 101.71 & 13.86 & & \\
& & & & \\
\hline
\end{tabular}

$t(225)=16.98, p<.0001,95 \%$ CI $[11.055,9.82]$. The difference in standardized PPVT scores between fall $(M=100.19, S D=14.19)$ and spring $(M=101.71$, $S D=13.86)$ was also statistically significantly different, $t(214)=2.82, p<.005$, 95\% CI $[.45,7.21]$. Mean differences between classrooms on the standardized PPVT- 4 between fall and spring varied by class $(M=1.68, S D=3.15)$, with classroom score differences ranging from gains as high as 7 points or losses of 4 points, and a correlation of .84 between the two time points. Only 6 of the 27 classrooms demonstrated losses.

Different types and frequencies of talk to promote word consciousness. Table 3 provides examples of the different types of word consciousness talk, and Table 2 provides descriptive statistics for the types of teacher talk identified across the 27 teacher transcripts in addition to other teacher quality variables. The word con-

Table 3. Word Consciousness Codes

\begin{tabular}{|c|c|c|}
\hline Category & Description & Examples \\
\hline Positively reinforcing word use & $\begin{array}{l}\text { Positively reinforcing word use with } \\
\text { verbal praise; the teacher refers to } \\
\text { positive word use explicitly }\end{array}$ & $\begin{array}{l}\text { "Bare, that is the magic word, } \\
\text { very good." } \\
\text { "Excellent. That was the word } \\
\text { we were looking for." } \\
\text { "Wow, nice job using our magic } \\
\text { word." }\end{array}$ \\
\hline Personal experience & $\begin{array}{l}\text { Connects words to students' personal } \\
\text { experience, asks students to think } \\
\text { about the word in the context of } \\
\text { their own experience }\end{array}$ & $\begin{array}{l}\text { "Do you know someone who is } \\
\text { comforting?" } \\
\text { "How might you feel if you were } \\
\text { hopeless?" } \\
\text { "Some of you might know what } \\
\text { a village is because you live in } \\
\text { one." } \\
\text { "What is something you have at } \\
\text { home that glimmers?" }\end{array}$ \\
\hline Affirming recognition & $\begin{array}{l}\text { Affirming students' recognition of } \\
\text { a word either verbally or with } \\
\text { tangible rewards }\end{array}$ & $\begin{array}{l}\text { "Wonderful job noticing that } \\
\text { new word!" } \\
\text { "Oh, great work finding that } \\
\text { word." }\end{array}$ \\
\hline
\end{tabular}


sciousness codes included reinforcing students' word use (e.g., "Wow! I like how you used our magic word active!"), affirming students' recognition of a word's meaning or use (e.g., "Kiss your brain, glimmer does mean sparkle or shine!"), and connecting students' experiences to words being discussed (e.g., "Can you think of something in your house that you really appreciate?"). Table 2 shows that these personal connections were used with high frequency in some classrooms (e.g., 30 times in a 20-minute time period) and not at all in other classrooms. By contrast to personal connections that were on average used $4.18(S D=9.19)$ times during a 20-minute period, affirming recognition and reinforcing word use were not particularly common, averaging $1.66(S D=2.14)$ and $1(S D=1.13)$ teacher comments during a 20-minute period, respectively.

The various types of teacher talk to promote word consciousness were correlated with each other and in some cases correlated with other teacher characteristics (see Table 4). That is, affirming recognition was positively correlated with reinforcing word use $(r=.54, p<.001)$ and making personal connections $(r=.16, p<.01)$, and reinforcing word use was positively correlated with personal connections $(r=.12$, $p<.05)$. Affirming recognition and reinforcing word use were positively but not statistically correlated with teacher sensitivity (i.e., $r=.009$ and $r=.07$, respectively, $p=n s$ ), and making personal connections was negatively correlated, although very weakly so, with teacher sensitivity $(r=-0.15, p<.05)$. The number of word types and instruction fidelity were positively and significantly correlated with reinforcing word use ( $r=.0 .29, p<.001$, and $r=0.28, p<.001$, respectively), with the number of word types also positively and significantly correlated with making personal connections $(r=.29, p<.0001)$. The majority of the correlations, with the exception of the correlation between instruction fidelity and the number of word types, were only weakly associated with each other. In subsequent analyses, we explore the three word consciousness indicators as a composite score, given the low base rate scores of affirming recognition and reinforcing word use. Moreover, the composite demonstrated a closer approximation of a normal distribution, with an absolute value of skewness index $\leq 3.0$ and absolute value of kurtosis index $\leq 10.0$ (Kline, 2005).

\section{Explanatory Power of Word Consciousness Talk for Student Vocabulary Growth}

To explore the association between word consciousness talk and students' general vocabulary scores at the end of kindergarten, we fit several multilevel models

Table 4. Correlations among Teacher Characteristics

\begin{tabular}{|c|c|c|c|c|c|c|}
\hline & 1 & 2 & 3 & 4 & 5 & 6 \\
\hline 1. Affirming & 1 & & & & & \\
\hline 2. Reinforcing & $.54^{\star * *}$ & 1 & & & & \\
\hline 3. Personal experience & $.16^{* *}$ & $.12^{*}$ & 1 & & & \\
\hline 4. Teacher sensitivity & .009 & .07 & $-.15^{*}$ & 1 & & \\
\hline 5. Word types & $.15^{*}$ & $.29^{* * *}$ & -.27 & $-.39^{* * *}$ & 1 & \\
\hline 6. Instruction fidelity & -.06 & $.28^{* * *}$ & $-.32^{* *}$ & $-.12^{\star}$ & $.52^{\star * *}$ & 1 \\
\hline
\end{tabular}


nesting students within classrooms. In Table 5, we provide our taxonomy of models. Our model building commenced with an unconditional model (Model 1; see Table 5), followed by stepwise integration of models, beginning with our controls (demographic variables associated with vocabulary performance, i.e., race/ethnicity and gender as well as initial PPVT scores at kindergarten entry; Model 2). Our controls included student characteristics found in other studies (Eccles, Wigfield, Harold, \& Blumenfeld, 1993) to be correlated with student language and literacy performance (i.e., gender and race); we also included students' initial vocabulary scores to account for individual differences in vocabulary at the start of kindergarten to explore average potential gain scores. Students' initial PPVT-4 score was group mean centered to facilitate interpretation of the model (O'Connell \& McCoach, 2008). Our subsequent models included our classroom-level controls (Model 3) instruction fidelity $^{1}$ and competing teacher characteristics (Model 4), including teacher sensitivity and word types, with the grand mean of all Level 2 predictors centered for interpretability. Last, we included our question predictor (Model 5) word consciousness. All interaction terms between the word consciousness codes and student-level characteristics were explored. Interaction terms were not statistically significant $(p<.05)$ and thus were not included in subsequent models.

Table 5. Taxonomy of Multilevel Models to Predict Students' General Vocabulary Knowledge at the End of Kindergarten

\begin{tabular}{|c|c|c|c|c|c|}
\hline & \multicolumn{5}{|c|}{ Model, $b(S E)$} \\
\hline & 1 & 2 & 3 & 4 & 5 \\
\hline \multicolumn{6}{|l|}{ Fixed effects: } \\
\hline Intercept & $101.02(1.70)^{\star * *}$ & $102.49(2.01)^{\star * *}$ & $103.43(1.98)^{\star * *}$ & $103.28(1.89)^{\star * *}$ & $103.59(1.79)^{* * *}$ \\
\hline Pre-PPVT & & $.72(.05)^{* * *}$ & $.72(.05)^{* * *}$ & $.72(.05)^{* * *}$ & $.71(.05)^{* * *}$ \\
\hline \multicolumn{6}{|l|}{ African } \\
\hline American & & $-.88(1.62)$ & $-.99(1.62)$ & $-.81(1.64)$ & $-.87(1.64)$ \\
\hline Hispanic & & $-2.54(1.49) \sim$ & $-2.66(1.50) \sim$ & $-2.63(1.50) \sim$ & $-2.86(1.49)^{\star}$ \\
\hline Asian & & $6.41(4.61)$ & $6.24(4.62)$ & $6.21(4.63)$ & $6.49(4.62)$ \\
\hline Female & & $.20(1.08)$ & $.23(1.08)$ & $.22(1.09)$ & $.07(1.09)$ \\
\hline \multicolumn{6}{|l|}{ Instruction } \\
\hline fidelity & & & $-8.00(8.18)$ & $-9.33(9.43)$ & $-6.82(4.62)$ \\
\hline Word types & & & & $.014(0.44)$ & $.015(.02)$ \\
\hline \multicolumn{6}{|l|}{ Teacher } \\
\hline sensitivity & & & & $3.11(1.59)^{\star}$ & $3.45(1.49)^{\star *}$ \\
\hline \multicolumn{6}{|l|}{ Word } \\
\hline consciousness & & & & & $.29(.15)^{*}$ \\
\hline \multicolumn{6}{|l|}{ Random effects: } \\
\hline Teacher & $70.83(20.77)^{* *}$ & $70.32(22.75)^{* *}$ & $66.93(21.95)^{* *}$ & $55.77(18.81)^{* *}$ & $46.89(16.50)^{* *}$ \\
\hline Student & $127.83(13.14)^{\star * *}$ & $52.34(5.61)^{* * *}$ & $52.40(5.62)^{* * *}$ & $52.83(5.70)^{* * *}$ & $52.97(5.73)^{* * *}$ \\
\hline \multirow[t]{2}{*}{ Goodness of fit } & $1,693.6$ & $1,441.5$ & $1,440.5$ & $1,408.90$ & 1405.00 \\
\hline & $\chi_{2}$ difference & $d f$ & $p$-value & & \\
\hline Model 1 versus 2 & 252.10 & 5 & .0001 & & \\
\hline Model 2 versus 3 & 1 & 1 & .32 & & \\
\hline Model 4 versus 3 & 31.60 & 2 & .0001 & & \\
\hline Model 5 versus 3 & 3.90 & 1 & .046 & & \\
\hline
\end{tabular}


In our final model (Model 5), both teacher sensitivity $(b=3.45, S E=1.49, p<$ $.01)$ and word consciousness $(b=0.29 S E=0.15, p<.05)$ were positively associated with gains in standardized vocabulary scores at the end of kindergarten, with a chi-square difference test indicating that this additional parameter explained statistically significant variance in the outcome, $\chi^{2}(1, N=215)=3.90, p<.05$ (Singer \& Willett, 2003). Thus, when controlling for student-level characteristics as well as teacher characteristics, word consciousness was positively and statistically significantly associated with students' gains on a standardized vocabulary measure. In other words, each increase in one additional use of talk to promote word consciousness was associated with an increase in students' PPVT scores, that is, a .29-point increase in that classroom at the end of kindergarten.

\section{Discussion}

This study explores one promising avenue for improving the vocabulary of kindergarten students and preventing these learners from falling behind: everyday teacher talk that promotes word consciousness. Our investigation to identify and document the prevalence of this kind of talk with younger word learners - operationalized as talk that reinforced students' use of words, affirmed students' recognition of word meanings, and helped students make personal connections to words - demonstrated that this kind of talk was positively associated with gains in vocabulary scores at the end of kindergarten. We elaborate in the sections that follow on the nature of word consciousness talk and its positive association with general vocabulary as well as on the implications of these findings for future teacher professional development and research.

\section{Promoting Word Consciousness in Kindergarten}

This study is unique in that it operationalized the construct of word consciousness in teacher-student interactions, as opposed to exploring this construct as it relates to activities. The types of teacher utterances to promote word consciousness that emerged in this study included teachers' comments that reinforced students' use of words, affirmed students' recognition of word meanings, and helped students make personal connections to words. Results from the present investigation support a positive relation between these types of talk that promote word consciousness and students' vocabulary knowledge at the end of kindergarten. This finding is consistent with theories that support the role of personal relevance for retaining new information (Gambrell, 2011) as well as engagement theories that posit that positive interchanges about words between students and teachers can motivate students to improve their performance (Guthrie \& Humenick, 2004; Guthrie \& Wigfield, 2000; Wasik \& Hindman, 2014), with the unique contribution of this work being that these relationships hold for more explicit talk about words, in particular, and word learning beyond words taught.

Similar to the work of Graves (2000), this research supports word consciousness as a separable and important ingredient in supporting word knowledge when taught with other evidence-based practices. Our finding supports the potential of 
teacher talk that encourages personal connections and verbal praise of students' use and recognition of words for general vocabulary knowledge, and as such encourages future research on the potentially differential impact of these kinds of discussions for proximal (target words) and distal (standardized vocabulary) outcomes. Importantly, word consciousness must be considered as one aspect of good vocabulary practice and should be used in conjunction with high-quality classroom practices more broadly. Work by Silverman (2007, p. 102) found that instructional approaches that solely "discuss target words in context and through personal experiences" were less effective for improving target word knowledge than approaches that combined semantic analysis and attention to spoken words and written forms of words.

Critical for informing future professional development around vocabulary instruction is that teachers observed in this study did not frequently engage in forms of verbal praise about words (i.e., affirming students' recognition of a word's meaning and positively reinforcing word use), with teachers averaging approximately one to two uses of this kind of talk per a 20-minute observation. Existing work on verbal praise of students' learning demonstrates a positive impact of this type of talk on elementary school students' perceptions of their ability (Blumenfeld, Pintrich, Meece, \& Wessels, 1982). In our study, focused on urban students, it is particularly worth considering the potential dynamic relationship between the use of verbal praise and student characteristics and competencies. Students in urban schools, on average, are at elevated risk of language and literacy difficulties (Lesaux, Harris, \& Sloane, 2012), with one argument being that incidences of verbal praise might be lower in our study because students in these schools may be less interactive or knowledgeable about words, which would provide fewer opportunities for teachers to reinforce positive word behaviors (Cotton, 1989). Therefore, the absence of this kind of talk may reflect the relatively shallow knowledge students had of the words being taught during vocabulary time, although it is worth noting that the schoolwide vocabulary program is intended for students with limited knowledge of the target words.

It is also possible that the dynamic nature of praise, in which the frequency of praise is related to the frequency of desired student behaviors, may reflect urban teachers' perceptions of students' competencies and not necessarily their actual skill. Given research on teachers' low expectations of minority students (Harry \& Klingner, 2006) and the different hiring practices of schools that serve traditionally underserved student populations (Lee, 2004), of interest is whether teachers' verbal praise or discussions about personal connections to words might have been more frequent in more affluent, suburban, and predominantly White schools, where teachers' expectations for their students may differ. Future research should explore the prevalence of these codes across schools with students and teachers from varying socioeconomic and ethnic backgrounds.

The absence of verbal praise in our study is particularly concerning given that this study, similar to studies that have proceeded it (Burchinal et al., 2008; Mashburn et al., 2008; Pianta et al., 2005), found that teachers' sensitivity to students' emotional and behavioral states was positively associated with student gains in vocabulary knowledge. It stands to reason that teachers who engage in more positive interactions with students across the school day will multiplicatively increase student learning. ${ }^{2}$ Future research that explores the prevalence of supportive talk (word 
consciousness talk and positive talk more broadly) should explicitly explore how these different kinds of talk may vary across divergent school contexts.

The essential role of affective feedback broadly was evident in this study in that both word consciousness talk and teacher sensitivity were positively associated with students' standardized vocabulary performance at the end of kindergarten (i.e., $12 \%$ of the total variability between classrooms in standardized vocabulary scores was attributable to teachers' word consciousness talk, and $23 \%$ of the total variability between classrooms in standardized vocabulary scores was attributable to teacher sensitivity). ${ }^{3}$ An exploration of the standardized beta weights for these two predicators also indicated a small (.21) and medium (.28) effect size for word consciousness and teacher sensitivity, respectively (Cohen, 1988; Snijders \& Bosker, 2012). Noteworthy is that few vocabulary intervention studies (investigations that tend to focus less on affective aspects of interventions) document large effect sizes for standardized vocabulary measures (Elleman, Lindo, Morphy, \& Compton, 2009; Marulis \& Neuman, 2010). Indeed, Elleman and colleagues' (2009) meta-analysis of vocabulary interventions found that the overall random weighted mean effect size on standardized vocabulary measures was .29 , with effects ranging from -.24 to .46. As such, while the effect in our study for word consciousness talk is considered a small effect, relative to other vocabulary practices, it seems analogous and thus relevant and important for documenting potentially important factors for vocabulary gains.

The unique variance explained by the teacher sensitivity subscale may also capture teachers' academic responsiveness, in addition to teachers' sensitivity to emotional needs broadly (i.e., affective components of teaching). Teacher sensitivity, as a subcomponent of the CLASS emotional support composite, is thought to capture "the extent to which teachers provide comfort, reassurance, and encouragement" (Downer et al., 2012, p. 25). However, in our study, which included a more directly analogous indicator of encouragement and reassurance for the target literacy outcome, teacher sensitivity continued to significantly predict unique variance in vocabulary outcomes. The unique contribution of this subscale may be explained by its other features - that is, beyond solely creating a comfortable and affirming environment for student and teacher interactions, teacher sensitivity captures teachers' awareness of students who need extra help and responsiveness to students' academic needs. Future research should explore and replicate the use of this construct in conjunction with affective indicators more directly tied to outcomes of interest to tease out the nature of the unique contribution of this subscale.

Another implication of this work particularly relevant for future professional development in promoting word consciousness talk is that making personal connections, the most frequently used type of talk in our study, is similar to other teacher practices thought to increase cognitive components of reading and thus is likely an area that teachers will absorb and implement with greater ease. For example, this kind of talk is related to strategies to increase students' reading comprehension by drawing on their background knowledge to help students make connections between new content and their prior knowledge (Tierney \& Pearson, 1985). In general, teacher training and curriculum tend to focus on the development of skills for learning more widely than on the will for learning (Guthrie, Wigfield, Barbosa, et al., 2004; Guthrie, Wigfield, \& Perencevich, 2004). As such, teachers may be more 
inclined, better trained, and more intuitively able to incorporate strategies that they associate with cognitive growth as opposed to affective growth. In this case, their knowledge of building on students' own experiences and prior knowledge - as a reading strategy - may have contributed to their applying this strategy more widely with vocabulary. Professional development should focus on explicitly making the connection between the use of this strategy for improving comprehension and word learning.

Moreover, encouraging for future work on increasing classroom interactions that support word consciousness is that talk that helps students make personal connections to words may solicit more interactive conversations with students, as demonstrated by the prevalence of these kinds of interactions in classrooms where teachers used personal connections. For example, in the Appendix, a teacher is talking with her class about the word option. To help students understand the word, she has the class think about an experience in which the word option is relevant for their everyday experiences (i.e., "What are some options a parent might give you?"). As students chime in providing personal examples of different food options their parents give them (e.g., chicken and rice vs. vegetables), students' comments also provide rich opportunities for the teacher to continue to clarify the meaning of the word by helping students pay attention to how the word is used and for whom, with this knowledge likely empowering students to use the word themselves. As is the case in this example, a student's response allows the teacher to support his or her class in attending to why the student is actually referring to options his mom has (i.e., "Sometimes she buys food. That's your mom's option. Sometimes she cooks food for you and sometimes she buys food"). Thus, helping students make personal connections may lead to more personal connection-related conversations and, as is the case in this example, can provide opportunities to attend to the word more carefully and in ways that promote students' own mastery in using the word in the future.

\section{Limitations}

This study marks a critical first step toward identifying teacher talk to support word consciousness for younger word learners. At the same time, we note several limitations to the present investigation. This study did not assess students' word consciousness; instead, we aimed to identify talk theorized to promote word consciousness. Our main interest was identifying teacher talk to promote word consciousness, given that there is still minimal work on what instructional talk that supports general word knowledge looks like for younger word learners (Coyne, McCoach, \& Kapp, 2007). Important for future work intended to capture students' word consciousness is the development of informal and standardized measures to assess early word learners' level of word consciousness. Recommendations by the National Reading Panel (2000) as well as by Pearson, Hiebert, and Kamil (2007) encourage the development of more sensitive vocabulary assessments. Pearson and colleagues (2007) emphasize that measures that assess more incremental growth in vocabulary are needed, and they bemoan the lack of sensitivity of present measures for documenting depth of word knowledge, which is likely associated with students' word consciousness. Once measures to assess students' level of interest and attention to words have been developed and validated, then the role of teacher 
talk as the key moderator of the relationship between student word consciousness and performance can be tested.

In addition, our study is not intended to capture a comprehensive list of the kinds of talk that support word consciousness but instead to provide a starting point for identifying this kind of talk in teacher utterances. It is possible that teachers during other parts of the day or in different academic settings or with different age groups may use language to promote word consciousness in other ways that did not emerge in this naturalistic study. Furthermore, this study focused explicitly on talk that supports students' positive word dispositions. We examined these affective aspects of word consciousness, as these are components that are commonly cited as important for word learning and rarely investigated empirically (Baumann et al., 2009). However, we would encourage future work to explore some of the more metacognitive aspects of word consciousness that are less agreed upon in the field and that have considerable overlap with existing research-based instructional approaches for word-learning strategies. Further work to clarify the construct of word consciousness will serve the field in identifying its unique contribution and provide insight for implementation of these practices.

It is also worth noting that our study was descriptive in nature and captures correlational data, and thus does not make causal claims regarding the impact of this kind of talk on student vocabulary learning. However, our findings provide compelling evidence of a potential relationship between word consciousness talk and general word knowledge as well as bolster existing assertions regarding the benefits of word consciousness talk.

Another limitation of the investigation is that only one teacher observation was used to capture teachers' talk. Our coding of predictors that were captured during a sole observation and not an average of multiple observations may have lowered the reliability of the predictors, introduced potential measurement error, and attenuated our correlations. However, given that significant correlations were found between these predictors and the vocabulary outcome as well as the mere breadth of factors captured, we believe our results still provide promising findings for vocabulary instruction and performance.

Last, our study did not conduct member checks with teachers to see if the prevalence or absence of certain kinds of talk were intentional or strategic. Future work should conduct interviews with teachers in conjunction with a fine-grained analysis of teacher utterances to explore how teachers understand their use or omission of certain kinds of talk and whether they attribute the characteristics of their speech to their knowledge of child development, teacher training, and/or values about language development and learning.

\section{Implications}

Increases in vocabulary knowledge improve reading comprehension skills and bolster academic success over the long term (RAND Reading Study Group, 2002). This article identifies and explores teacher talk that promotes word consciousness as one means of improving students' general vocabulary knowledge. Documenting these different types of talk can provide important insight for potentially guiding teacher preparation program curriculum intended to support teachers' use of im- 
pactful classroom talk. Our research provides unique evidence to categorize teacher talk to promote students' interest and attention to words (Stahl \& Shiel, 1999). Teacher preparation programs should prioritize explicit instruction on language use to promote word consciousness, as this study shows that the majority of teachers were not frequently engaging in talk that was associated with student gains in standardized vocabulary scores. Our investigation provides compelling support for the use of teacher talk that praises students' recognition of words and use of words as well as helps students make personal connections to words. Although previous studies have included these kinds of talk as part and parcel of their intervention, few have explored this approach at the utterance level. This study is the first to demonstrate the contribution of these types of word consciousness talk about vocabulary to general word knowledge. We encourage future work to continue to explore students' will to learn words, in addition to their skill in learning words, so that teacher language can support a healthy diet of cognitive and affective components of word learning.

\section{Appendix}

\section{Making Personal Connections}

Teacher: What are some options a parent might give you? Think about your parent, your mom or your dad. Sometimes they give you an option. What kind of option do they give you sometimes?

Alex: Food.

Teacher: A food option? What kind of foods? They say "Do you want to eat ... vegetables or..."

Isabella: Chicken and rice.

Teacher: And what do you pick? What do you pick for your option?

Isabella: Chicken and rice.

Teacher: What is another option a parent might give you, James?

James: Sometimes she cooks for me.

Teacher: She does?

James: Sometimes she buys food.

Teacher: Sometimes she buys food. That's your mom's option. Sometimes she cooks food for you and sometimes she buys food.

\section{Notes}

Sabina Rak Neugebauer is assistant professor of teaching and learning at Temple University in the College of Education. Perla B. Gámez is an assistant professor in the Department of Psychology at Loyola University Chicago. Michael D. Coyne is a professor of special education in the Neag School of Education, University of Connecticut. Ingrid T. Cólon is assistant professor of early childhood education at the University of the District of Columbia. D. Betsy McCoach is professor and program coordinator of the measurement, evaluation, and assessment program at the University of Connecticut. Sharon Ware is an assistant professor of special education at the University of Saint Joseph. Correspondence may be sent to Sabina Rak Neugebauer at sabina.neugebauer@temple.edu. 
1. The negative but not statistically significant coefficient for instruction fidelity emerged in our previous longitudinal research in which we consistently found an interaction between at-risk status (based on standardized vocabulary scores) and surface fidelity on student curriculumspecific vocabulary (Coyne, McCoach, Ware, \& Rattan, 2015; Cuticelli, 2016; Neugebauer, Coyne, McCoach, \& Ware, 2017). EORV was designed as an intervention, and thus it stands to reason that it differentially supports the vocabulary development of students requiring additional support.

2. The number of word types was not a statistically significant predictor in the present analysis. However, we do not conclude from this that the number of different words is not a key ingredient for increasing vocabulary. To the contrary, a wealth of research supports language sophistication as a central indicator (Dickinson \& Porche, 2011; Hoff, 2006). The absence of a statistically significant positive association in the present investigation is likely a function of the fact that teachers' word use was influenced by the teachers' adoption of the vocabulary curriculum. Indeed, we found a relatively high correlation between instruction fidelity and word types, a correlation that is expected and intended by design, given that adherence to the word list and activities likely increased how many different target words were discussed in a 20-minute period. Our observations focused solely on the vocabulary part of the day; it is reasonable that this indicator would have been more predictive if measured during class time not devoted explicitly to vocabulary.

3. To calculate the appropriate pseudo $r^{2}$ values for teacher sensitivity and word consciousness, models were refit to contain only the significant predictors (i.e., initial vocabulary scores and the two teacher level predictors) from the final model. As such, we were able to estimate the proportion of variance explained at the classroom level and do so in a manner that would avoid changes in nonstatistically significant predictors across models that might influence the assessment of the contribution of our variables of interest (Snijders \& Bosker, 2012).

\section{References}

Bandura, A. (1997). Self-efficacy: The exercise of control. New York: W. H. Freeman.

Baumann, J. F., Ware, D., \& Edwards, E. C. (2009). Bumping into spicy, tasty, words that catch your tongue: A formative experiment on vocabulary instruction. In M. F. Graves (Ed.), Essential readings on vocabulary instruction (pp. 153-169). Newark, DE: International Reading Association.

Beck, I. L., \& McKeown, M. G. (2004). Elements of reading vocabulary: Teacher's guide level A (Harcourt Supplemental Publishers, Rigby Steck-Vaughn, Item Number 0-7398-8458-1). Austin, TX: Steck-Vaughn.

Beck, I. L., McKeown, M. G., \& Kucan, L. (2002). Bringing words to life: Robust vocabulary instruction. New York: Guilford.

Blachowicz, C., \& Fisher, P. (2004). Vocabulary lessons. Educational Leadership, 61, 6-69.

Blumenfeld, P. C., Pintrich, P. R., Meece, H., \& Wessels, K. (1982). The role and formation of selfperceptions of ability in elementary classrooms. Elementary School Journal, 82, 401-420.

Bowers, E., \& Vasilyeva, M. (2011). The relation between teacher input and lexical growth of preschoolers. Applied Psycholinquistics, 32, 221-241.

Bryant, D., Clifford, R., Early, D., Howes, C., \& Pianta, R. (2002, November). What is prekindergarten? Preliminary findings from a six-state prekindergarten study. Seminar conducted at the meeting of the National Association for the Education of Young Children, New York.

Burchinal, M., Howes, C., Pianta, R., Bryant, D., Early, D., Clifford, R., . . Barbarin, O. (2008). Predicting child outcomes at the end of kindergarten from the quality of pre-kindergarten teacher-child interactions and instruction. Applied Developmental Science, 12(3), 140-153. doi:10.1080/10888690802199418

Cohen, J. (1988). Statistical power analysis for the behavioral sciences. Mahwah, NJ: Erlbaum.

Cotton, K. (1989). Expectations and student outcomes. Portland, OR: Northwest Regional Educational Laboratory. 
Coyne, M., McCoach, D. B., Ware, S., \& Rattan, S. (2015). Evaluating the efficacy of a supplemental kindergarten vocabulary intervention implementation with a tiered instruction framework. Washington, DC: Society for Research on Educational Effectiveness.

Coyne, M. D., McCoach, D. B., \& Kapp, S. (2007). Teaching vocabulary to kindergarten students during shared storybook readings: A comparison of rich instruction, basic instruction, and incidental exposure. Learning Disabilities Quarterly, 30, 74-88.

Coyne, M. D., McCoach, D. B., Loftus, S., Zipoli, R., Jr., \& Kapp, S. (2009). Direct vocabulary instruction in kindergarten: Teaching for breadth vs. depth. Elementary School Journal, 110, $1-18$.

Coyne, M. D., McCoach, D. B., Loftus, S., Zipoli, R., Ruby, M., Crevecoeur, Y., ... Kapp, S. (2010). Direct and extended vocabulary instruction in kindergarten: Investigating transfer effects. Lournal of Research on Educational Effectiveness, 3, 93-120.

Cuticelli, M. N. (2016). Teacher effects on kindergarten students' vocabulary learning (Unpublished doctoral dissertation). University of Connecticut, Storrs.

Dickinson, D. K., \& Porche, M. V. (2011). Relationship between language experiences in preschool classrooms and children's kindergarten and fourth grade language and reading abilities. Child Development, 82, 870-886.

Dickinson, D. K., \& Smith, M. W. (1994). Long-term effects of preschool teachers' book readings on low-income children's vocabulary and story comprehension. Reading Research Ouarterlv, 29, 104-122.

Downer, J. T., López, M. L., Grimm, K. J., Hamagami, A., Pianta, R. C., \& Howes, C. (2012). Observations of teacher-child interactions in classrooms serving Latinos and dual language learners: Applicability of the Classroom Assessment Scoring System in diverse settings. Early Childhood Research Quarterly, 27(1), 21-32. doi:10.1016/j.ecresq.2011.07.005

Duffy, G., Roehler, L., \& Rackliffe, G. (1986). How teachers' instructional talk influences students' understanding of lesson content. Elementary School Journal, 87, 3-16.

Dunn, D. M., \& Dunn, L. M. (2007). Peabody Picture Vocabulary Test (4th ed.). Bloomington, MN: NCS Pearson.

Eccles, J. S., Wigfield, A., Harold, R. D., \& Blumenfeld, P. (1993). Age and gender differences in children's self and task perceptions during elementary school. Child Development, 64, 830847 .

Elleman, A. M., Lindo, E. J., Morphy, P., \& Compton, D. L. (2009). The impact of vocabulary instruction on passage-level comprehension of school-age children: A meta-analysis. Lournal of Research on Educational Effectiveness, 2(1), 1-44. doi:10.1080/19345740802539200

Feldman, K., \& Kinsella, K. (2005). Narrowing the language gap: The case for explicit vocabulary instruction. New York: Scholastic.

Fernald, A., Marchman, V. A., \& Weisleder, A. (2013). SES differences in language processing skill and vocabulary are evident at 18 months. Developmental Science, 16, 2, 234-248.

Gambrell, L. B. (2011). Seven rules of engagement: What's most important to know about motivation to read. Reading Teacher, 65, 172-178.

Gámez, P. B., \& Lesaux, N. K. (2015). Early-adolescents' reading comprehension and the stability of the middle school classroom language environment. Developmental Psychology, 51, $447-458$.

Gersten, R., Compton, D., Connor, C. M., Dimino, J., Santoro, L., Linan-Thompson, S., .. . Tilly, W. D. (2009). Assisting students struggling with reading: Response to intervention and multitier intervention in primary grades. Washington, DC: U.S. Department of Education Institute of Educational Sciences.

Graves, M. F. (2000). A vocabulary program to complement and bolster a middle-grade comprehension program. In B. M. Taylor, M. F. Graves, \& P. van den Broek (Eds.), Reading for meaning: Fostering comprehension in the middle grades (pp. 116-135). New York: Teachers College Press.

Graves, M. F. (2006). The vocabulary book. New York: Teachers College Press.

Graves, M. F., \& Watts-Taffe, S. M. (2002). The place of word consciousness in a research-based vocabulary program. In A. E. Farstrup \& S. J. Samuels (Eds.), What research has to say about reading instruction (3rd ed., pp. 140-165). Newark, DE: International Reading Association. 
Graves, M. F., \& Watts-Taffe, S. (2008). For the love of words: Fostering word consciousness in young readers. Reading Teacher, 62, 185-193.

Guthrie, J. T. (2004). Teaching for literacy engagement. Iournal of Literacv Research, 36, 1-29.

Guthrie, J. T., Hoa, A. L. W., Wigfield, A., Tonks, S. M., Humenick, N. M., \& Littles, E. (2007). Reading motivation and reading comprehension growth in the later elementary years. Contemporary Educational Psychology, 32, 282-313.

Guthrie, J. T., \& Humenick, N. M. (2004). Motivating students to read: Evidence for classroom practices that increase motivation and achievement. In P. McCardle \& V. Chabra (Eds.), The voice of evidence in reading research (pp. 329-354). Baltimore: Brookes.

Guthrie, J. T., \& Wigfield, A. (200o). Engagement and motivation in reading. In M. L. Kamil, P. B. Mosenthal, P. D. Pearson, \& R. Barr (Eds.), Reading research handbook (Vol. 3, pp. 403-424). Mahwah, NJ: Erlbaum.

Guthrie, J. T., Wigfield, A., Barbosa, P., Perencevich, K. C., Taboada, A., Davis, M. H., . . . Tonks, S. (2004). Increasing reading comprehension and engagement through concept-oriented reading instruction. Iournal of Educational Psvchology, 96, 403-423.

Guthrie, J. T., Wigfield, A., \& Perencevich, K. C. (Eds.). (2004). Motivating reading comprehension: Concept-oriented reading instruction. Mahwah, NJ: Erlbaum.

Harry, B., \& Klingner, J. (2006). Why are so many minorities in special education? Understanding race and disability in schools. New York: Teachers College Press.

Hart, B., \& Risley, R. T. (1995). Meaningful differences in the everyday experience of young American children. Baltimore: Brookes.

Hoff, E. (2006). How social contexts support and shape language development. Developmental Review, 26, 55-88.

Huttenlocher, J., Vasilyeva, M., Waterfall, H. R., Vevea, J. L., \& Hedges, L. V. (2007). The varieties of speech to young children. Developmental Psychology, 43(5), 1062-1083. doi:10.1037 /o012-1649.43.5.1062

Johnston, T. C., \& Kirby, J. R. (2006). The contribution of naming speed to the simple view of reading. Reading and Writing, 19, 339-361.

Kieffer, M. J., \& Lesaux, N. K. (2010). Morphing into adolescents: Active word learning for English language learners and their classmates in middle school. Lournal of Adolescent and Adult Literacy, 54, 47-56.

Kline, R. B. (2005). Principles and practice of structural equation modelling (2nd ed.). New York: Guilford.

Krippendorff, K. (2012). Content analysis: An introduction to its methodology (3rd ed.). Thousand Oaks, CA: Sage.

Kucan, L. (2012). What is most important to know about vocabulary? Reading Teacher, 65(6), $360-366$.

Lee, C. (2004). Racial segregation and educational outcomes in metropolitan Boston. Cambridge, MA: Civil Rights Project at Harvard University.

Lesaux, N. K., Harris, J. R., \& Sloane, P. (2012). Adolescents' motivation in the context of an academic vocabulary intervention in urban middle school classrooms. Iournal of Adolescent and Adult Literacy, 56(3), 231-240.

MacWhinney, B. (2010). The CHILDES Project: Tools for analyzing talk. Mahwah, NJ: Erlbaum.

Marulis, L. M., \& Neuman, S. B. (2010). The effects of vocabulary intervention on young children's word learning: A meta-analysis. Review of Educational Research, 80(3), 300-335. doi:10.3102/0034654310377087

Mashburn, A. J., Pianta, R. C., Hamre, B. K., Downer, J. T., Barbarin, O. A., Bryant, D., . . . Howes, C. (2008). Measures of classroom quality in prekindergarten and children's development of academic, language, and social skills. Child Development, 79, 732-749.

Maxwell, J. A. (2005). Qualitative research design: An interactive approach (2nd ed.). Thousand Oaks, CA: Sage.

McKeown, M. G., \& Beck, I. L. (2004). Direct and rich vocabulary instruction. In J. F. Baumann \& E. J. Kame'enui (Eds.), Vocabulary instruction (pp. 13-27). New York: Guilford.

McKeown, M. G., \& Beck, I. L. (2014). Effects of vocabulary instruction on measures of language processing: Comparing two approaches. Earlv Childhood Research Ouarterlv, 29(4), 520-530. 
McKeown, M. G., Beck, I. L., \& Apthorp, H. (2011, April). Examining depth of processing in vocabulary lessons. Poster presented at the American Educational Research Association Conference, New Orleans.

McKeown, M. G., Crosson, A. C., Artz, N. J., Sandora, C., \& Beck, I. L. (2013). In the media: Expanding students' experience with academic vocabulary. Reading Teacher, 67(1), 45-53.

Mercer, N. (2002). The art of interthinking. Teaching Thinking, 7, 8-11.

Nagy, W., \& Scott, J. (2000). Vocabulary processing. In M. Kamil, P. Mosenthal, P. D. Pearson, \& R. Barr (Eds.), Handbook of reading research (Vol. 3, pp. 269-284). Mahwah, NJ: Erlbaum.

National Reading Panel. (200o). Report of the National Reading Panel-Teaching Children to Read: An evidence-based assessment of the scientific research literature on reading and its implications for reading instruction. Washington, DC: National Institute of Child Health and Human Development.

Neuendorf, K. (2002). The content analysis guidebook. Thousand Oaks, CA: Sage.

Neugebauer, S. R., Coyne, M., McCoach, B., \& Ware, S. (2017). Teaching beyond the intervention: The contribution of teacher language extensions to vocabulary learning in urban kindergarten classrooms. Reading and Writing, 30, 543-567.

O’Connell, A. A., \& McCoach, D. B. (2008). Multilevel modeling of educational data. Charlotte, NC: Information Age.

Ouellette, G., \& Beers, A. (2010). A not-so-simple view of reading: How oral vocabulary and visual-word recognition complicate the story. Reading and Writing, 23, 189-208.

Pearson, P. D., Hiebert, E. H., \& Kamil, M. L. (2007). Vocabulary assessment: What we know and what we need to learn. Reading Research Ouarterlv, 42(2), 282-296. doi:10.1598/RRQ.42.2.4

Pianta, R., Howes, C., Burchinal, M., Bryant, D., Clifford, R., Early, D., . . Barbarin, O. (2005). Features of pre-kindergarten programs, classrooms, and teachers: Do they predict observed classroom quality and child-teacher interactions? Applied Developmental Science, 9(3), 144159.

Pianta, R. C. (2003). Standardized observations from pre-K to 3 rd grade: A mechanism for improving access to high-quality classroom experiences and practices during the $P-3$ years. New York: Foundation for Child Development.

Pianta, R. C., La Paro, K. M., \& Hamre, B. K. (2008a). Classroom Assessment Scoring System (CLASS) manual, $\mathrm{K}-3$. Baltimore: Brookes.

Pianta, R. C., LaParo, K. M., \& Hamre, B. K. (2008b). Classroom Assessment Scoring System (CLASS) manual, pre-K. Baltimore: Brookes.

Pintrich, P. R., \& Blumenfeld, P. C. (1985). Classroom experiences and children's self-perceptions of ability, effort and conduct. Lournal of Educational Psychology, 77, 646-657.

RAND Reading Study Group. (2002). Reading for understanding: Toward an R\&D program in reading comprehension. Santa Monica, CA: Author.

Rowe, M. L. (2012). A longitudinal investigation of the role of quantity and quality of childdirected speech in vocabulary development. Child Development, 83(5), 1762-1774. doi:10 $.1111 /$ j.1467-8624.2012.01805.x

Salvia, J., \& Ysseldyke, J. E. (1998). Assessment (7th ed.). Boston: Houghton Mifflin.

Sarafino, E. P., Russo, A., Barker, J., Consentino, A., \& Titus, D. (1982). The effect of rewards on intrinsic interest: Developmental changes in the underlying processes. Lournal of Genetic Psychology, 141, 29-39.

SAS (Version 9.3) [Computer software]. Cary, NC: SAS Institute.

Schreier, M. (2012). Qualitative content analysis in practice. Los Angeles: Sage.

Scott, J., \& Nagy, W. (2004). Developing word consciousness. In J. Baumann \& E. Kame'Enui (Eds.), Vocabulary instruction: Research to practice. New York: Guilford.

Scott, J. A., Miller, T. F., \& Flinspach, S. L. (2012). Developing word consciousness: Lessons from highly diverse fourth-grade classrooms. In J. Baumann \& E. Kame’enui (Eds.), Vocabulary instruction: From research to practice (2nd ed.). New York: Guilford.

Scott, J. A., \& Nagy, W. E. (1997). Understanding the definitions of unfamiliar words. Reading Research Quarterly, 32, 184-200.

Silverman, R. (2007). A comparison of three methods of vocabulary instruction during readalouds in kindergarten. Elementarv School Journal, 108, 97-113. 
Silverman, R. D., Proctor, C. P., Harring, J. R., Doyle, B., Mitchell, M. A., \& Meyer, A. G. (2014). Teachers' instruction and students' vocabulary and comprehension: An exploratory study with English monolingual and Spanish-English bilingual students in grades $3^{-5}$. Reading Research Quarterlv, 49, 31-60.

Singer, J., \& Willett, J. (2003). Applied longitudinal data analysis: Modeling change and event occurrence. New York: Oxford University Press.

Snijders, T. A. B., \& Bosker, R. (2012). Multilevel analysis: An introduction to basic and advanced multilevel modeling (2nd ed.). Thousand Oaks, CA: Sage.

Snow, C. E., Burns, M., \& Griffin, P. (Eds.) (1998). Preventing reading difficulties in young children. Washington, DC: National Academies.

Snow, C. E., \& Dickinson, D. K. (1991). Skills that aren't basic in a new conception of literacy. In A. Purves \& E. Jennings (Eds.), Literate systems and individual lives: Perspectives on literacy and schooling. Albany: SUNY Press.

Stahl, S. A., \& Shiel, T. R. (1999). Teaching meaning vocabulary: Productive approaches for poor readers. Sacramento: California State Board of Education.

Tierney, R. J., \& Pearson, D. (1985). Learning to learn from texts: A framework for improving classroom practice. In H. S. Singer \& R. B. Ruddell (Eds.), Theoretical models and processes of reading (pp. 860-878). Newark, DE: International Reading Association.

Tracey, D. H., \& Morrow, L. M. (2006). Lenses on reading. New York: Guilford.

Vygotsky, L. S. (1986). Thought and language. Cambridge, MA: MIT Press.

Walsh, M. (2014). The relationship between word consciousness and vocabulary growth and achievement in fourth and fifth graders (Unpublished doctoral dissertation). National Louis University, Chicago.

Wasik, B. A., \& Hindman, A. H. (2014). Understanding the active ingredients in an effective preschool vocabulary intervention: An exploratory study of teacher and child talk during book reading. Earlv Education and Development, 25(7), 1035-1056.

Zipke, M. (2008). Teaching metalinguistic awareness and reading comprehension with riddles. Reading Teacher, 62(2), 128-137.

Zipoli, R. P., Coyne, M. D., \& McCoach, D. B. (2011). Enhancing vocabulary intervention for kindergarten students: Strategic integration of semantically related and embedded word review. Remedial and Special Education, 32, 131-143. 